This is the accepted manuscript of the article, which has been published in Style. 2017, 51(3), 337-356. http://dx.doi.org/10.1353/sty.2017.0029

\title{
Dementia, Positioning and the Narrative Self
}

Matti Hyvärinen

UNIVERSITY OF TAM PERE

Ryoko Watanabe

WASEDA UNIVERSITY

\begin{abstract}
The narrative self has historically been identified with long, autobiographical narratives. However, medical and neuropsychological studies have portrayed Alzheimer's disease $(\mathrm{AD})$ from the perspective of a gradual loss of memory and selfhood. During the progression of the disease, the traditional concept of the narrative self loses much of its relevance. This article suggests that positioning analysis offers powerful tools for locating the agentive, embodied and fragmentarily narrative self of patients with advanced dementia. Videotaped occupational therapy sessions from a Japanese nursing home are used to study borderline cases of the narrative self that challenge the dominant models for theorizing selfhood. The two women studied have advanced dementia and yet possess an urge to tell about and visit their pasts - the remains of their narrative selves. The article suggests that "narrative" in the narrative self should be understood as a verb or an adjective, and not exclusively as a noun.
\end{abstract} Keywords: dementia, Alzheimer's disease, positioning, narrative self, embodied self, autobiographical self.

The narrative self has historically been identified with long, autobiographical narratives displaying the narrator's life-course from birth to the moment of telling (M acIntyre; M cAdams). At the same time, medical and neuropsychological studies have pictured dementia and Alzheimer's disease (AD) from the perspective of a gradual loss of memory and the entirety of selfhood. Increasing numbers of scholars have explored the varied narrative resources of individuals with early to mid-stage AD. During the progression of the disease, the traditional concept of the narrative self loses much of its relevance, and the embodied self becomes more prominent. Dementia narratives thus provide an important test case for narrative theories on the self and for the methods to study it. This article suggests that positioning analysis offers powerful tools for locating the agentive, embodied narrative self at the stage when the patients fail to tell full autobiographical stories. Using videotaped occupational therapy sessions and other ethnographic material from a Japanese nursing home, we study bo rderline cases of the narrative self that challenge the dominant models for theorizing selfhood. In the studied cases, continuous positioning as an activity becomes a more relevant aspect of the narrative self than 
the conventionally emphasized autobiographical narrative as a finished whole. This article first assesses the rationale of current theories on the narrative self, second, offers a positional analysis of a test case that disputes the overall validity of these theories, and third, proposes a redirection in the study of narrative selves to accommodate a wider diversity of selves, including those of people with AD. The implications to the overall study of and theories on the narrative self remains a topic for further studies, but our results make evident the need to revisit the founding assumptions of the autobiographical self.

\section{Narrative Self Reconsidered}

Dementia poses inescapable problems for the dominant idea of the narrative self. From the seminal work of Alasdair Maclntyre onwards, the concepts of the narrative self and identity have continuously been attached to a more or less coherent story running from birth-often including family histories before one's birth-to the present time of telling: "[I]n the modern world in which we all live, identity is a life story [. . . ] The emphasis in this book is on how the story develops, from birth to old age" (McAdams 5; Giddens 54). The philosopher Marya Schechtman agrees, proposing that "constituting an identity requires that an individual conceives of his life having the form and the logic of a story-more specifically, the story of a person's life-where 'story' is understood as a conventional, linear narrative" (96). These and many other formulations of the narrative self and identity-all of which are drafted for the purpose of theorizing the self in distinctively human terms-seem to run into severe problems when applied to people facing the advanced stages of dementia and AD. Either we decide that people with severe memory problems no longer have a narrative self at all, or we revise the terms of the narrative self so that it is not necessarily equated with extensive, autobiographical stories. In this article, we suggest the latter and propose the model of narrative positioning to offer an alternative understanding of the narrative self as an interactive ability to relate to social situations and to the storyline projections involved in them.

This change of emphasis also radically changes the way people with dementia are perceived. Biomedical, neuropsychological, and cognitive studies have previously painted a rather grim, even totalizing picture of the deterministically advancing and devastating loss of memory, 
words and the entirety of selfhood that is associated with dementia (Brockmeier; Hydén, "Towards"; Kontos, "Embodied selfhood", "Ethnographic reflections"). The hegemonic view of dementia was paradoxically expressed in 1986, when Cohen and Eisdorfer published an important book "to help families and other care givers understand what their options are in caring for the patient" (15), under the title The Loss of Self.

Alzheimer's disease is considered to be the most frightening condition that faces the older population in the 21st century [. . . ] and it is a much-feared stigmatising label that carries with it a sentence of social death [. . . The source of these fears is the assumption that individuals with Alzheimer's disease or other dementias lose what, according to western culture, defines our humanness: selfhood. (Kontos, "Ethnographic reflections" 829)

While this biomedical approach "focuses principally on what people cannot do and explains dysfunction of all kinds as outcomes of the disease process alone," (Sabat 24-25) and thematizes dementia in terms of the interminable process of loss, ethnographically oriented researchers of dementia have by contrast generated a number of critical, balancing counterarguments to the biomedical-cum-neuropsychological model. Instead of focusing on loss and dysfunction in this article, we want to study the last remaining elements of narration and sensemaking through embodied interaction, and to document the role of the remaining agentive self at the point where "narrative self" in the particular sense of autobiographical sense fails.

Research on dementia narratives has helped us to understand how narration faces difficulties over time (Hamilton, Conversations, "Narrative as Snapshot"), how the coherence of narration depends radically on the context (Ramanathan), how central narrative skills and functions abide in spite of difficulties with event sequencing (Hydén, "Identity"), and, more generally, how to better understand the lifeworlds of people with dementia (Castro and Clark-M cGhee; Hydén, "Cutting Brussels sprouts"; Sabat). These studies typically portray people with dementia as active agents whose lives contain many more nuances, activities, and achievements than the starkly dramatized perspective of the loss of the self. 
The idea of the loss of self is most explicitly criticized from the perspective of the embodied self (Hydén, "Bodies", “Towards"; Kontos, “Ethnographic reflections”, “Embodied Selfhood”). Kontos draws on Merleau-Ponty's phenomenology of the body and Bourdieu's theory of habitus in pointing out that the self needs to be understood as an embodied whole. Kontos' argument cuts through issues of memory, self, and narrative:

$\ll$ Q >Explicit in the current construction of Alzheimer's disease is the assumption that memory impairment caused by cognitive deficiencies leads to a steady loss of selfhood. The insistence that selfhood is the exclusive privilege of the sphere of cognition has its origins in the modern western philosophical tradition that separates mind from body, and positions the former as superior to the latter. This dichotomy suggests a fundamental passivity of the body, since it is primarily cognition that is held to be essential to selfhood. (Kontos, "Ethnographic reflections" 829.

Kontos's discussion of the embodied self is essential for this article, as she extends the range of the self further than the traditional conception of the narrative self. If the body is so vital an element for memory and the self, the deterioration of linguistic skills and the capacity to tell proper stories do not as such indicate the loss of selfhood. The embodied and agentive self endures in social manners, rituals, and greetings, as is richly documented in Kontos' ethnographic work.

M ichael Bamberg's version of positioning analysis similarly focuses both on the storied past, which can be named "the narrative content," and the interactional and embodied positioning going on at the time of the telling (Bamberg, "Positioning with Davie Hogan"). We argue that the role of this interactional positioning becomes increasingly salient when the capacity to tell extensive, autobiographical narratives gradually wanes. Interactional positioning also contains the bodily aspect, allowing for the inclusion of embodied action in the analysis of the event of telling. Even at an advanced stage of $A D$, the analysis of narrative positioning can be used in productive ways to chart the remains of the narrative self and the remaining, agentive role of the embodied self. The narrative self, at its core, may therefore more importantly signify the active reenactment and revisiting of narrative positions than the mere recounting of past events as such. From this perspective, the narrative self is not formed by an autobiographical 
narrative, or several of them, but it is rather a form of-and the capacity for-continuous positioning action.

\section{Analytical Model, Research Questions, and Data}

Positioning theory was introduced to social psychology in the early 1990s by Davies and Harré and van Langenhove and Harré. These authors took the previously theoretical concept of subject position and gave it its current active form, in order to replace the rather rigid concept of "role." Van Langenhove and Harré suggest that "[f]luid positionings, not fixed roles, are used by people to cope with the situation they usually find themselves in" (17). In accordance with the tenet of discursive psychology, Harré highlights that positioning "is not determined by competence alone but also by having rights and duties in relation to items in the local corpus of sayings and doings" (51).

Bamberg ("Structure and performance", "Positioning with Davie Hogan") has developed positioning theory by drawing ideas from narratology and discourse analysis (DA). He suggests the following three analytic levels for the study of talk-in-interaction narratives:

1. Story. How are characters positioned on the level of the story in the reported events?

2. Telling. How do the speakers position themselves and others on the level of interaction?

3. Identity. How do the speakers position themselves with respect to the "Who am I?" question?

Bamberg's own formulations of the third level vary somewhat between his texts, yet he anchors the third level to more general societal discourses and more "portable"-that is continual and stable aspects-of identity. Bamberg suggests that while the positions on level 2 are strictly situational, here and now, the positions on level 3 refer to positions people arguably carry from one situation and context to another. (Deppermann 5-6; Day and Kjaerbeck 19; De Fina, "Positioning level 3" 40-46)

Bamberg's model is narratively attuned for noticing the difference between levels 1 and 2-the time of events and the time of telling. Researchers drawing primarily from conversation analysis (CA) tend to find level 2 the most relevant, and express doubts about the documentation of level 3 (Day and Kjaerbeck). Positioning analysis is an integral part of the "small story research" 
that adds its relevance to the current study (Bamberg, "Stories: Big or small"; Georgakopoulou). Small story research focuses on stories that are short, incomplete, or otherwise atypical in terms of the conventional, Labovian model of oral stories. Equally, small stories are investigated within the frame of talk-in-interaction and thus as jointly produced, not as renderings that are complete and independent from local tasks and interactions (De Fina and Georgakopoulou 385). For Bamberg and CA-oriented scholars, the preferred material for positioning analysis consists of what they call "naturally occurring" conversations. The data for this article was not originally transcribed in such a way that would allow a nuanced DA or CA of the interactional details. Nevertheless, as the conversations have been video recorded, the constant flow of bodily movements is available for analysis.

When it comes to people with dementia, the nuanced study of small stories is important to avoid focusing on mere lack and impairment. Positioning can be enacted bodily (e.g., by doing or resisting exercise), which extends the applicability of the analysis. The distinction between analytic levels 1 and 2 is both problematic and crucial because of the problems of memory. As a borderline form of narration, dementia narratives challenge both narrative theory and methods. For this study, the perspective of positioning analysis suggests three research questions:

1. How do the past, story-level positions profile in the data?

2. To what extent do the patients with advanced AD position themselves in agentive ways during the course of the studied interaction?

3. Is it possible to document elements of "portable" identities in the talk and interaction of the studied women with advanced AD.

Watanabe collected the data for this study by using ethnographic observations and interviews in a Japanese nursing home from 2004 to 2006. The home accommodates about 100 elderly residents and routinely provides short-term rehabilitation for the residents and visitors. Three occupational therapists and one care worker cooperatively conducted therapy sessions for approximately five to ten clients, mainly in a therapy room arranged as an open space (Fig. 1). The researcher videotaped their sessions for 28 days and interviewed one of the target therapists, Kawaguchi, five times. The data consist of about 150 hours of videotaped 
recordings, eight hours of interviews, and complementary field notes. Watanabe translated the interviews into English, but in addition to that, the metaphorical expressions and connotations of the Japanese culture were checked several times during the writing process. No transcription is fully transparent, least so between different languages, yet we regard the undertaking to understand to be valuable, despite the limitations.

Kawaguchi is an experienced occupational therapist who is well known for creating dramas with children and elderly people with disabilities. These dramas, however, are no random plays of fiction. Social workers have interviewed the families of people with dementia in advance, and the therapist crafts the dramas based on this information. For example, he knows that M rs. N. has been a farmer and has sold vegetables, and from which part of the country she has come. The two studied women (Mrs. N. and Mrs. O.) were over 85 years old during the data collection and suffered from similar health conditions, including advanced $A D$ and difficulty in walking and communicating. Both visited the home for short-stay care-for one or two weeks a few times each year. They sometimes participated in social programs such as singing old songs or free group conversation in the home, but they often needed communication aids. For both participants, the environment was relatively strange and challenging (Ramanathan), not a familiar site of storytelling.

For ethical reasons, permission for this study was sought and obtained from all participants, including the therapists, people with $A D$, other elderly residents, and their family (if needed). The researcher had one-to-one contacts with the participants to provide research information in the form of printed material and to ask for their permission to be included in the study. The therapists and the caregiver also provided a clear explanation to the clients before their sessions. At that time, the relevant research ethics committees did not exist in Japan, so the project was conducted based on the participants' freely volunteered informed consent.

Fig. 1 The arrangement of a therapy room.

\section{The Case of "The Fine Face"}

Hydén has discussed the potentially disturbing vocalizations usual "in later stages of Alzheimer's disease" (Hydén, "Non-verbal Vocalizations"). This varied noisemaking includes 
"screaming and other kinds of sounds," (Hydén, "Non-verbal Vocalizations" 135) and is often experienced as being disturbing in family and care contexts. Hydén's advice is to study these non-verbal vocalizations as occasioned by interaction and within the local context of interaction (Hydén, "Non-verbal Vocalizations" 143). M rs. N. has obvious difficulties with her voice, and in the first excerpt, the therapist tries to show her a nicer way of laughing, only to be entirely misunderstood. The therapist, Kawaguchi, has the objective of getting M rs. N. and M rs. O. to participate in simple physical exercises (both have declined requests to do so earlier). In order to achieve this, he tries to engage these women with advanced $A D$ in storytelling and consensual conversation.

Excerpt 1: Showing a fine face

1 Therapist: Hello.

2 Mrs. N.: Hello.

3 Therapist: How are you?

4 M rs. N.: Yes, I am fine.

5 Therapist: Well, please show your fine face.

6 M rs. N.: I can't show my fine face any more.

7 Therapist: Well. [says gently; in local dialect] please show your lovely face.

$8 \mathrm{M} \mathrm{rs}$. N.: Oh it is a very lovely face.

9 Therapist: [starts to massage her left leg]

10 M rs. N.: \{\} want to laugh.

11 Therapist: [looks at her] \{You\}want to laugh

12 M rs. N.: \{\} want to laugh.

13 Therapist: When you want to laugh

14 Mrs. N.: Yes?

15 Therapist: It's better to laugh like this ha ha ha [demonstrates laughter]

16 Mrs. N.: No.

17 Therapist: Well, smile ...

$18 \mathrm{M} \mathrm{rs.} \mathrm{N}$.: I dislike being laughed at very much. 
19 Therapist: Do you? Well, let's smile.

20 Therapist: [leans his head to the right and left with a smile]

$21 \mathrm{Mrs}$. N.: [leans her head to the right and left with a smile]

22 Therapist: [looks back at M rs. B] Isn't she lovely?

23 M rs. B.: [looks at the therapist and nods] She's lovely.

As Hamilton (Conversations 61-68) points out, automatic linguistic formulations help people with advanced dementia to keep up conversations as these automatic, stereotypical formulas remain in use even after the flexible elements of speech start to disappear. M rs. N. has no problem at all in exchanging polite greetings and giving adequate answers (lines 2 and 4), even though she does not smile, thus departing from Japanese cultural expectations. This lack of a smile elicits the therapist's query about her mood and "fine face" (Line 5). At first, this produces her negative answer, expressing her mood. Here, M rs. N. adopts the rather withdrawn and uncooperative position of an old woman with no reason to smile. However, as Kawaguchi switches his tone and dialect, and repeats his query in a new form, M rs. N. willingly consents. Kawaguchi starts now to massage her feet, and M rs. N. announces that she wants to laugh. They act in harmony until line 13, when the therapist tries to introduce the hypothetical case of laughing. We see that the meaning of this hypothetical proposal is entirely misunderstood by M rs. N. (lines 16 and 18), as she perceives herself to be the target of the laughter. Most likely, she fails to understand the hypothetical structure and reacts to the artificiality of the test laugh on the embodied level. The therapist moves from the hypothetical laughing to actual smiling in the present situation (line 19), and tilts his head right and left. Immediately, M rs. N. is with him, smiling and moving her head in the same way. Now the therapist draws in their immediate audience, M rs. B., to receive her corroboration of M rs. N's loveliness. The positive emotional state is shared and consolidated by this move.

This first conversational episode already testifies to M rs. N's ongoing activity in interactional positioning. Before the episode, she had already rejected Kawaguchi's and other therapist's requests to take part in the exercises. She formally takes her position as a polite conversationalist (lines 2 and 4), yet only reservedly and without a smile. Equally, she 
straightforwardly rejects pleasantries and the imagined negative position when she feels that she is a target of laughter (lines 16 and 18). She seems to have difficulty in staying in contact with other people, and reacts starkly when losing the contact. Regardless of the advanced $A D$, she expresses an active self, eager to engage in interaction and defend her own position. Thus far, there has been very little by way of explicit autobiographical storytelling. However, one basic element of narrativity, namely experientiality, is powerfully present throughout this episode, in particular in lines 6, 8, 10, and 18 (Fludernik; Herman). As David Herman characterizes experientiality, "it can be argued that narrative is centrally concerned with qualia, a term used by philosophers of mind to refer to the sense of 'what it is like' for someone or something to have a particular experience" (14). This experientiality is supported by a primordial, embodied way of understanding others. As the philosopher Daniel Hutto maintains, "[h]uman children exhibit a special responsiveness to the intentional attitudes of others early on" (21). Shaun Gallagher, another phenomenologically oriented philosopher, similarly points out that "infants are capable of discerning emotions and intentions in postures, movements, facial expressions, gestures, vocal intonations, and actions of others" (293). This primary intersubjectivity does not disappear in adulthood; on the contrary, the interaction analyzed here suggests that it may regain a prominent role in interaction when newer levels of language use fail due to advanced AD. M rs. N. often fails to understand Kawaguchi's words, but systematically reacts to his tone, dialect, movements, and touch.

\section{From Shouting to Competence: No Money}

Shortly after the previous episode, the therapist makes a new attempt to engage M rs. N. in the physical exercises. Previously, he had succeeded by referring to the wishes of Mrs. N's son. The therapist tries this again, but the reaction is entirely different this time.

\section{Excerpt 2.1. No Money}

1 Therapist: One more time [touching her lap]

2 M rs. N.: Yes. [nods]

3 Therapist: If you do the stand-up exercise.

4 Mrs. N.: Yes. 
5 Therapist: I think your son will become happier.

6 M rs N.: [tilts her head to the left]

7 Therapist: What do you think?

8 M rs. N.: I DON'T HAVE MUCH M ONEY.

9 Therapist: [waves his left hand] Well, you don't need money [looks at her gently]

10 M rs. N.: THERE IS NOTHING TO DO W ITHOUT M ONEY.

Based on the material, it is hard to say what exactly triggers such an agitated reaction. Two things, however, seem obvious. This sudden shouting is not arbitrary; it is part of the interaction, and it is received as such, as we will see a little later. By shouting, M rs. N. indicates that she has concerns that are not being responded to during the conversation. Both of the sentences resemble Hamilton's (Conversations 61-77) relatively automatic speech: they echo sentences M rs. N. has heard and possibly used many times earlier in her life. In these sentences, the past is powerfully present. These sentences are typically used in tense social situations, and in a tense and loud voice.

Kawaguchi's reaction to this dilemma, the shouting and despair, is amazing. He invents a pretend play of buying and selling vegetables, positioning the participants of the conversation in a radically new way:

Excerpt 2.2. No money (continued)

11 Therapist: You know [touches her foot]

12 M rs. N.: Yeah.

13 Therapist: Later ...

14 M rs. N.: [nods]

15 Therapist: I will come to pick up your radish.

$16 \mathrm{M} \mathrm{rs.} \mathrm{N.:} \mathrm{[tilts} \mathrm{her} \mathrm{head} \mathrm{to} \mathrm{the} \mathrm{left]}$

17 Therapist: You know, the radish

18 M rs. N.: [nods]

19 Therapist: You have many of them, don't you?

20 M rs. N.: I think so. 
21 Therapist: [laughs and puts his head down]

22 Mrs. N.: [smiles]

23 Therapist: Well [puts his right hand on her lap] well, the radish seems OK.

24 M rs. N.: Well, so.

25 Therapist: For me, yes, now vegetables are expensive.

26 Mrs. N.: Yes. [nods]

27 Therapist: Since \{\} can't buy $\{$ them $\}$

28 Mrs. N.: Yes. [nods]

29 Therapist: [nods] In exchange for doing the stand-up exercise.

30 Mrs. N.: Yes.

31 Therapist: Later

Starting with the radishes and asking for M rs. N.'s confirmation that she recognizes them (line 17) and has them for sale (lines 19 and 20), Kawaguchi involves her in the play and ensures her positive mood (lines $20,22,24,26$, and 28). On line 25 , the therapist positions himself as dependent on M rs. N. and her vegetables. Here we have the membership categories of producer (farmer, seller) and consumer (buyer). After beginning this play, Kawaguchi and M rs. N. continue it for a good while. The successful continuation of the play informs us at least of the fact that M rs. N. seems to be genuinely pleased about being invited into the interaction and her past position. She is now in contact with the therapist, and is no longer a lonely woman without money.

However easy it is to recognize the ongoing positioning, it is more difficult to locate it indisputably on any particular level of Bamberg's model. These positions are given and taken over the course of the interaction; therefore, they should be on level 2. However, considering M rs. N's involvement in the play, it is possible to argue that she is living out her past position on story level 1. Indeed, it is even possible that she has now identified with the position of an independent farmer in the sense of positioning level 3. It is noteworthy that the therapist's strategy is to suggest role-like positions that can connect past and the present identities. The important difference between levels 1 and 2 concerns the anchoring of the position of the farmer in the past or present. To look at the issue differently, is it possible to evaluate the 
referentiality of the game? Is M rs. N. referring to some actual past farming the therapist knows she engaged in, or is the play entirely invented over the course of the conversation? Does the play take place only in the here and now of the nursing home, or is the then and there of the farm embedded?

The pretend play indeed has two sections when the referentiality of M rs. N's position becomes salient. She is strict in only selling products she has farmed, not whatever the therapist wants to buy. This becomes clear when Kawaguchi attempts to buy strawberries and M rs. N. says it is impossible (Watanabe 96). In this very liminal sense, we can argue that over this pretend play, M rs. N. is playing out her past and her past positions. Through the play, she seems to have contact with the remains of her narrative self, thus founding her positioning on level 3-not only on level 2 interaction-but also on level 1, the past life she has lived.

During their play, they encounter two further problems. In the first case, Mrs. N. cannot count the number of vegetables she has given, and gets confused. Nevertheless, she clearly says, "it was hard to count." After the therapist's "I see," she repeats in a loud voice "YES, YES, YES, YES," and makes plosive noises (Watanabe 94). The use of loud and non-verbal vocalization is an obvious result of conversational confusion. Shortly after this episode, a new kind of dilemma is encountered.

\section{Excerpt 2.3. Apples}

68 Therapist: What kinds of vegetables will you give?

69 M rs. N.: [nods] An apple.

70 Therapist: AN APPLE! [laughs and dabs his head] \{\}\}said, vegetables. Vegetables. [smiles and cups his hands in front of her]

71 M rs. N.: [smiles] Vegetables?

72 Therapist: Yes. [nods]

$73 \mathrm{M} \mathrm{rs}$. N.: Are vegetables different from an apple?

74 Therapist: Vegetables ... [tilts his head] an apple seems a fruit.

75 M rs. N.: That's because ...

76 Therapist: Yes. [nods]

77 M rs. N.: \{\}\}can't ( ) 
78 Therapist: Oh, I see.

79 M rs. N.: Yes. [nods]

80 Therapist: Well, it's no problem.

$81 \mathrm{Mrs}$. N.: Please let it be all right.

82 Therapist: Yes. [nods]

83 M rs. N.: THANK YOU, THANK YOU, THANK YOU SO MUCH.

This episode begins with a change of rules. So far, Kawaguchi has named a vegetable and M rs. N. has accepted and handed it over. This time, the therapist asks what she could give, and she eagerly offers an apple. Kawaguchi finds the idea of an apple being a vegetable funny, and cannot, in the new situation, hide his laughter. However, the laughter harshly contravenes the conversational expectations in the situation. M rs. N. becomes confused, and both of them try to solve the dilemma from line 70 to $79 . \mathrm{Mrs}$. N. displays remarkable intellectual resources on line 73 by openly posing the problem of categorization. On line 81 she actively, if obscurely, expresses her will to move past the dispute by her meta-communicative expression. She remains confused and closes the episode paradoxically by raising her voice but using a formulaic, polite expression.

The confusion above is about membership categorization. Kawaguchi was drawing from the standard cultural distinction between fruits and vegetables, while M rs. N. obviously had something entirely different in mind. Arguably, abstract categories become difficult to maintain with advanced AD. M rs. N. is most likely concerned with the categories "things I grow," and "things I don't grow." Therefore, while engaging seriously in the pretend play, she is again telling about her past position as a farmer and producer of apples. Later in the conversation, the therapist accepts the apple as an important part of their play, and M rs. N. ends up doing her exercises. While the therapist is standing up and helping M rs. N. to stand, she thanks him and suddenly adds: "My rice field has a nap," and repeats this obviously important message once again in her next turn. It is impossible to understand the full content of this sentence when the comment is left without scaffolding questions (Becker; Bruner). Yet she confirms her role as a farmer (positioning, level 3 ), and she wants to deliver a message about her rice field (positioning, level 1), even if the meaning of the remark remains unclear. 


\section{Schoolyard Memories}

In his interview, Kawaguchi says that creating "a scene, as in a drama play" and systematically reacting to what the people with dementia say and do are central to his method of communicating with people with AD (Watanabe 119, 131). With M rs. N., he did not ask for a story: he created the dramatic setting of buying and selling. Dramas include roles; therefore, it is not far-fetched to claim that he is systematically playing a game of positioning by attributing roles. Identifiable positions seem to activate people with dementia; they activate their memories and encourage them to tell at least snippets of stories. With M rs. O., he manages to elicit easily recognizable fragments of narrative.

Excerpt 3: In the Schoolyard

$1 \mathrm{Mrs.}$ O.: [finishes singing the song]

2 Therapist: Good.

3 M rs. 0.: Let's sing like this.

4 Therapist: Well, that song was sung many times in your school days, wasn't it?

5 Mrs. O.: Yes.

6 Therapist: Yeah.

7 Mrs. O.: \{\} sang.

8 Therapist: Where ... In the schoolyard or the gym?

9 M rs. O.: [puts her left hand over her mouth] That's right.

10 Therapist: Well, there was the head teacher, wasn't there?

11 Mrs. 0.: Yes, there was the head teacher properly.

12 Therapist: Yes.

13 M rs. 0.: \{He\}said, "ABOUT TURN!"

14 Therapist: Oh, I see. "Attention!”

15 M rs. 0.: Yeah. [lifts her left hand] "Attention!" [waves her left hand] "Turning right." We often did it.

16 Therapist: I see.

17 M rs. 0.: The head teacher \{said\} later, "EVERYONE BECOM ES GOOD AT IT." 
18 Therapist: $\{$ You $\}$ were praised.

19 M rs. 0.: $\{$ We $\}$ were praised. [smiles]

M rs. O's singing occasions the dramaturgical positioning the therapist chooses to work with. He frames the time (school years), the places (yard, the gym), and the positional catego ries relevant within the scene (head teacher). He does not need to mention schoolchildren or teachers; the category of head teacher is enough to invite all the other relevant past categories as well. M rs. 0 . does not need to mention her position as a schoolgirl, but by enacting the position she is able to tell about her experience. She is partly able to tell this story in such a lively manner because of the many stereotypical, often repeated expressions available that work to enhance the authentic atmosphere of her story. Mrs. O. embodies a narrative self, even when she is far beyond the capacity of giving a full account of the course of her life (On categories; Silverman 77-97).

On the story level 1, M rs. 0. positions herself as a schoolchild, and as one who became good at singing and enacting the patriotic ceremony, and was praised for it. On the interactional level 2 , she also takes an active role. By using a loud voice in the right places, she not only enlivens the stereotypical past expressions, she also rhetorically catches the attention of her audience. Immediately after the quoted passage, Kawaguchi invites her to do the exercises, but she resolutely declines the offer. Later, she resists Kawaguchi's request simply by closing her eyes and pretending to be asleep, but eventually she too consents to do the exercises (Watanabe 104-107).

What the therapist contributes above on lines $8,10,14$, and 18 has often been characterized by Bruner's (254) term "scaffolding" (Hydén, "Cutting Brussels sprouts"). By scaffolding, the parent helps the child's language use by providing "models of the expected dialogue from which he can extract selectively what he needs for filling his role in discourse." According to Becker, scaffolding has a particular role in learning how to tell experience narratives. Becker indicates that many children who are able to tell a whole fantasy story until its resolution need scaffolding by the peer audience when telling about their own experience. The Labovian narrative elements of orientation, resolution, and evaluation are often omitted, and the child only accounts for the complication (Labov). Becker maintains that these missing elements are 
the last to appear in children's experience stories, and the logic of their acquisition is conversational and scaffolded, rather than derived from listening to fairy tales. With dementia, the stories increasingly seem to be similarly reduced to the core element. A good example was M rs. N's emphatically repeated, strange narrative clause "M y rice field has a nap." Without scaffolding questions, its content remains a mystery. Such clauses remain conversationally inadequate and need help in establishing the orientation, resolution, and the point of the story. With M rs. O., the therapist manages to invite something that Riessman has called "habitual narrative," which accounts for important, recurrent activity without particular complication. Even with M rs. O., it is the therapist who suggests the evaluation (line 18). Therefore, her positioning on level 3 partly rests on the input from the other participant in the conversations, but she is nevertheless clearly involved.

\section{Discussion}

The use of positioning analysis in the analyses of therapeutic discussions with women with advanced dementia helps to portray these women as predominantly active, agentive participants of conversations. The scaffolding strategy adopted by the therapist can be termed dramaturgical positioning. In terms of level 1 positioning, he kept offering conventional, rolelike positions (farmer, schoolgirl). The interactional, level 2 positioning was more fluid and swift. On this level, the continuous embodied positioning was a fundamental element of the interaction. Rejecting or doing the suggested exercises, closing the eyes, tilting the head, using a loud voice, and reactions to the therapists massage, smile and tones were all vital parts of the conversation and position-taking. Because the suggested story-level anchoring positions were rather social roles, their connection to more general societal discourses (independent farmer, patriotic schoolgirl) on level 3 seems obvious.

The two old women in this study had been diagnosed with advanced AD. M rs. N. was practically unable to produce any narrative sentences, at least in the studied context, while M rs. 0 . showed a more extensive capacity to tell. Nevertheless, there is no doubt about the existence of their embodied, agentive selves, intentions, and continuity of person in both cases. Yet their utterly fragmented and sparse ways of telling about their pasts is in stark contrast to the traditional conceptions of the narrative self and identity. 
If the narrative self is understood, in the conventional way, as "the self displayed in a big narrative," or a collection of thick narrative content, these women hardly possess much of a narrative self. Instead of a careful creation of a storyworld (Herman), or even a disruption within this storyworld, the studied dementia sufferers seem to focus on taking a position or role within the storyworld. This position-taking, however, is displays strong experientiality. The alternative to the identification of the narrative self and big, autobiographical narrative is to renounce the assumption of narrative as a noun (Hydén, "Identity" 47): if we move toward understanding "narrative" as a verb or an adjective in "narrative selves," we can envision a self that communicates and is constituted with the help of narratives and storytelling. We can now recognize that both of these women with advanced dementia and AD still possessed the urge to tell about and visit their pasts-the margins of their narrative selves. The traditional conception of the narrative self, instead, would render them "selfless."

The analytical findings of this article suggest the study of the narrative self needs to engage more with the research traditions of embodied selves and narrative as interaction. The results demonstrate that positioning theory offers the methodological tools to achieve this. Whether the results based on our test case are generalizable beyond people with dementia or across cultural and linguistic areas requires further study. However, the need and possible direction for such further studies is now evident.

Matti Hyvärinen is Professor of Sociology, University of Tampere, Finland. He has studied the conceptual history of narrative, the narrative turns and interdisciplinary narrative theory. He is the coeditor of the volumes Narrative Theory, Literature, and New M edia. Narrative M inds and Virtual Worlds (Routledge 2015), The Travelling Concepts of Narrative (Benjamins 2013), and Beyond Narrative Coherence, (Benjamins 2010). He has published in Partial Answers, Qualitative Inquiry and Narrative Works, and in several edited volumes, including the entry on narrative genres in the Handbook of Narrative Analysis, edited by De Fina and Georgakopoulou (Wiley, 2015). 
Ryoko Watanabe is a lecturer of e-learning courses in the School of Human Sciences at Waseda University, Japan. She received her doctoral training in Japan and Finland and attained her PhD in 2016 from the University of Oulu. She specializes in educational and lifelong developmental psychology, and her research focus is on the relationships between people with dementia and their therapists, their teaching-learning processes, and the development of therapists' expertise in applying narrative approaches. $4 \mathrm{BIO}$.

\section{References}

Bamberg, M ichael. "Positioning between Structure and Performance." Journal of Narrative and Life History, vol. 7, no. 1-4, 1997, pp. 335-42.

- - - "Positioning with Davie Hogan. Stories, Tellings, and Identities." Narrative Analysis: Studying the Development of Individuals in Society, edited by Colette Daiute, and Cynthia Lightfoot, Sage, 2004, pp. 135-57.

--_. "Stories: Big or Small-Why Do We Care?." Narrative Inquiry, vol. 16, no. 1, 2006, pp. 139-47.

Becker, Tabea. "The Role of Narrative Interaction in Narrative Development." Narrative Interaction, edited by Uta M. Qasthoff, and Tabea Becker, John Benjamins, 2005, pp. 93-111.

Bruner, Jerome. "The Role of Dialogue in Language Acquisition." The Child's Conception of Language, edited by Anne Sinclair, et al., Springer, 1978, pp. 241-56.

Castro, M aria, and Kitty Clark-M cGhee. "A Narrative Analysis of Poetry Written from the Words of People Given a Diagnosis of Dementia." Constructing Narratives of Continuity and Change, edited by Hazel Reid, and Linden West, Routledge, 2015, pp. 144-58.

Cohen, Donna, and Carl Eisdorfer. The Loss of Self. W. W. Norton, 1986.

Davies, Bronwyn, and Rom Harré. "Positioning: The Discursive Production of Selves." Journal for the Theory of Social Behaviour, vol. 20, no. 1, 1990, pp. 43-63.

Day, Dennis, and Susanne Kjaerbeck. "'Positioning' in the Conversation Analytic Approach." Narrative Inquiry, vol. 23, no. 1, 2013, pp. 16-39.

De Fina, Anna. "Narratives in Interviews-The Case of Accounts." Narrative Inquiry, vol. 19, no. 2, 2009, pp. 233-58.

- - . "Positioning Level 3: Connecting Local Identity Displays to Macro Social Processes." Narrative Inquiry, vol. 23, no. 1, 2013, pp. 40-61.

De Fina, Anna, and Alexandra Georgakopoulou. "Analysing Narratives as Practices."

Qualitative Research, vol. 8, no. 3, 2008, pp. 379-87.

Deppermann, Arnulf. "Positioning in Narrative Interaction." Narrative Inquiry, vol. 23, no. 1, 2013, pp. $1-15$.

Fludernik, M onika. Towards a 'Natural' Narratology. Routledge, 1996.

Gallagher, Shaun. "Two Problems of Intersubjectivity." Narrative and Folk Psychology, edited by Daniel D. Hutto, Imprint Academic, 2009, pp. 289-308.

Georgakopoulou, Alexandra. Small Stories, Interaction and Identities. John Benjamins, 2007.

Giddens, Anthony. M odernity and Self-Identity: Self and Society in the Late M odern Age. Polity Press, 1991.

Hamilton, Heidi. Conversations with an Alzheimer's Patient. Cambridge UP, 1994.

- - - "Narrative as Snapshot. Glimpses into the Past in Alzheimer's Discourse." Narrative Inquiry, vol. 18 , no. 1, 2008, pp. 53-82. 
Harré, Rom. "Positioning as a M etagrammar for Discursive Story Lines." Telling Stories: Language, Narrative and Social Life, edited by Deborah Schiffrin, et al., Georgetown UP, 2010, pp. 51-55. Herman, David. Basic Elements of Narrative. Wiley-Blackwell, 2009.

Hutto, Daniel D. "Folk Psychology as Narrative Practice." Narrative and Folk Psychology, edited by Daniel D. Hutto, Imprint Academic, 2009.

Hydén, Lars-Christer. "Identity, Self, Narrative." Beyond Narrative Coherence, edited by Matti Hyvärinen, et al., John Benjamins, 2010, pp. 33-48.

- - . "Non-Verbal Vocalizations, Dementia and Social Interaction." Communication \& M edicine, vol. 8, no. 2, 2011, 135-44.

- - - "Bodies, Embodiment and Stories." Doing Narrative Research. edited by Andrews, Molly, Corinne Squire and Maria Tamboukou. Los Angeles: Sage, 2012, pp. 126-41.

- - - "Towards and Embodied Theory of Narrative and Storytelling." The Travelling Concepts of Narrative, edited by Matti Hyvärinen, et al., John Benjamins, 2013, pp. 227-44.

- - - "Cutting Brussels Sprouts: Collaboration Involving Persons with Dementia." Journal of Ageing Studies, vol. 29, 2014, pp. 115-123.

Kontos, Pia C. "Embodied Selfhood. An Ethnographic Exploration of Alzheimer's Disease." Thinking About Dementia: Culture, Loss, and the Anthropology of Senility, edited by Annette Leibing, and Lawrence Cohen, Rutgers UP, 2006, pp. 195-217.

- - - . "Ethnographic Reflections on Selfhood, Embodiment and Alzheimer's Disease." Ageing \& Society, vol. 24, 2004, pp. 829-49.

Labov, William. Language in the Inner City. Basil Blackwell, 1972.

MacIntyre, Alasdair. After Virtue: A Study in M oral Theory. University of Notre Dame Press, 1984.

M cAdams, Dan P. The Stories We Live By: Personal M yths and the Making of the Self. The Guilford Press, 1993.

Ramanathan, Vai "Narrative Well-Formedness in Alzheimer's Discourse: An Interactional Examination across Settings." Journal of Pragmatics, vol. 23, 1995, pp. 395-419.

Riessman, Catherine Kohler. Divorce Talk: Women and M en M ake Sense of Personal Relationships. Rutgers UP, 1990.

Sabat, Steven R. "The Person with Dementia as Understood through Stern's Critical Personalism." Beyond Loss: Dementia, Identity, Personhood, edited by Lars-Christer Hydén et al., Oxford UP, 2014, pp. 24-38.

Schechtman, M arya. The Constitution of Selves. Cornell UP, 1996.

Silverman, David. Harvey Sacks: Social Science and Conversation Analysis. Polity Press, 1998.

van Langenhove, Luke, and Rom Harré. "Introducing Positioning Theory." Positioning Theory: M oral Contexts of Intentional Action, edited by Rom Harré, and Luk van Langenhove, Blackwell, 1999, pp. 14-31.

Watanabe, Ryoko. Listening to the Voices of Dementia. The Therapist's Teaching-Learning Process through Co-Construction of Narrative and the Triadic Relationship with Alzheimer's Disease Sufferers. Universitatis Ouluensis, 2016. 